\title{
Bus Rapid Transit Features and Deployment Phases for U.S. Cities
}

\author{
Luis David Galicia, Ruey Long Cheu \\ The University of Texas at El Paso
}

Randy B. Machemehl, The University of Texas at Austin Hongchao Liu, Texas Tech University

\begin{abstract}
Bus Rapid Transit (BRT) systems are becoming popular in congested cities around the world. Since this mode of transportation is still evolving, there is a lack of clear definition of what constitutes a BRT system. This paper reviews the BRT systems around the world and characterizes their infrastructure and operational features. The most common features found are those that lead to travel time reduction or ridership attraction relative to regular bus services. However, not all the features must be implemented for a BRT system to be successful. Based on the features reviewed, this research recommends three sets of features that correspond to three phases of deployment in U.S. cities, depending on the project budget, time frame, users, and traffic and corridor characteristics.
\end{abstract}

\section{Introduction}

What is a Bus Rapid Transit (BRT) system? The U.S. General Accounting Office describes a set of elements that include exclusive bus highways and lanes, High Occupancy Vehicle (HOV) lanes, technological and street design improvements, traffic signal prioritization, better stations and/or bus shelters, fewer stops, faster service, and cleaner, quieter, and more attractive vehicles (GAO 2001). The Fed- 
eral Transit Administration defines BRT as "an enhanced bus system that operates on bus lanes or other transitways in order to combine the flexibility of buses with the efficiency of rail" (FTA 2007). In the "BRT Planning Guide" (Wright 2004), BRT is defined as "a high-quality bus-based transit system that delivers fast, comfortable, and cost-effective urban mobility through the provision of segregated rightof-way infrastructure, rapid and frequent operations, and excellence in marketing and customer service." The Transit Cooperative Research Program (TCRP) Report 90 defines BRT as "a flexible, rubber-tired rapid-transit mode that combines stations, vehicles, services, running ways, and Intelligent Transportation System (ITS) elements into an integrated system with a strong positive identity that evokes a unique image" (Levinson et al. 2003a). The Transit Capacity and Quality of Service Manual (TCQSM) states that "BRT is a complete rapid transit system that combines flexible service and new technologies to improve customer convenience and reduce delays" (Kittelson \& Associates et al. 2003). With such broad definitions, it is difficult for system designers, transportation engineers, and planners to explain $B R T$ to the policy makers and the public. If BRT really includes a spectrum of system types and features, how does one describe the BRT system concept?

This research performs a comprehensive review of major BRT systems in cities around the world. The review of BRT systems focused on their infrastructure and operational features relative to regular bus service. With an understanding that BRT systems may evolve differently in the U.S. cities, the selected BRT systems reviewed are grouped into U.S. and non-U.S. systems. Based on the lessons learnt, three levels of BRT systems that could be deployed in stages in U.S. cities are recommended. With a clear understanding of the BRT features and deployment phases, transportation agencies and transit operators are able to plan, implement, or evaluate a BRT system more effectively and distinguish it from conventional bus service.

\section{BRT Systems Reviewed}

The technical documents reviewed included reports, manuals, handbooks, web sites, and presentation slides published primarily in English and available at public sources. They covered the major BRT systems in North and South America and Austrasia, as shown in Table 1. More than 100 publications were reviewed. 
Table 1. List of BRT Systems Reviewed

\begin{tabular}{|c|c|c|c|}
\hline \multicolumn{2}{|l|}{ U.S. BRT Systems } & \multicolumn{2}{|c|}{ Non-U.S. BRT Systems } \\
\hline City & BRT System Name & City & BRT System Name \\
\hline Albuquerque, NM & Rapid Ride & Adelaide, Australia & North East Busway \\
\hline Boston, MA & Silver Line & Beijing, China & BRT Line 1 \\
\hline Eugene, OR & EMX & Bogotá, Colombia & TransMilenio \\
\hline Honolulu, $\mathrm{HI}$ & City Express & Brisbane, Australia & $\begin{array}{l}\text { South East and Inner } \\
\text { Northern Busway }\end{array}$ \\
\hline Las Vegas, NV & North Las Vegas MAX & Curitiba, Brazil & BRT Curitiba \\
\hline Los Angeles, CA & Metro Rapid Orange Line & Hang Zhou, China & BRT Line B1 \\
\hline Miami, FL & BUSWAY & Jakarta, Indonesia & TransJakarta \\
\hline New York, NY & Albany-Schenectady & Mexico City, Mexico & Metrobus \\
\hline Orlando, FL & LYMMO BRT & Leon, Mexico & Optibus \\
\hline Pittsburgh, PA & BUSWAY & Ottawa, Canada & Transitway \\
\hline Kansas City, KS & MAX & Quito, Ecuador & Ecovía and Trole \\
\hline Santa Clara, CA & VTA Rapid 522 & Sydney, Australia & $\begin{array}{l}\text { Liverpool-Parramatta } \\
\text { Transitway }\end{array}$ \\
\hline San Francisco, CA & Bay Area BRT & Sao Paulo, Brazil & BRT Sao Paulo \\
\hline Virginia, VA & Capital Beltway Proposal & Santiago, Chile & Transantiago \\
\hline
\end{tabular}

\section{Common BRT Features}

BRT features (also known as elements) are physical and operational characteristics that make BRT systems stand out from regular bus services. The features vary among the BRT systems in different cities and depend on factors such as local policy preference, customer needs, land use, weather, financial resources, etc. (GTZ 2006). The common BRT features may be grouped into infrastructure and operational features. BRT infrastructure features are those related to the physical facilities along corridor, including:

- Guideway

- Stations (bus stops, terminal and other boarding facilities)

- Park-and-ride facilities

- Surrounding land use (also known as transit oriented development) 
These features are normally under the jurisdiction of the local infrastructure provider.

- BRT operational features include:

- Vehicles

- Route coverage and service frequency

- ITS technologies applied to BRT

- Fare collection

- Operating speed methods

The operational features are generally controlled by the service provider(s).

\section{Infrastructure Features}

\section{Guideway}

The most potentially significant but costly BRT infrastructure feature is provision of dedicated or exclusive lanes. The lanes may be at-grade or grade-separated. Collectively, they are referred to as guideways. Guideways help to improve operating speed, schedule reliability, and headway control between BRT vehicles. Guideways appear more frequently outside the U.S.; implementation in the U.S. is rare because of the high cost of right-of-way acquisition. Thus, limited-length exclusive tunnels (e.g., the Metro Bus Tunnel in Seattle), combinations of dedicated lanes, and mixed flow or contra-flow lanes (e.g., in Boston) appear more feasible. Engineers must be innovative to develop relatively low-cost guideway designs that will fit into the local street configurations. At least some of the advantages of exclusive guideways can be provided through less costly innovations such as bus-onshoulder bypasses, short dedicated guideway segments, queue jumpers, and signal priority systems. The number of necessary lanes and overpass sections should be carefully designed according to the temporal distribution of expected demand. In some cases, such as Seoul and Sao Paulo, exclusive BRT lanes are congested due to bus bunching (GTZ 2006). One of the most common BRT detriments is the excessive maintenance required in the guideway's pavement. The Los Angeles Orange Line and Mexico City's MetroBus have been forced to temporarily close some sections of their routes to rebuild the guideway pavement. In both cases, this inconvenience has appeared after less than one year of operation (Hidalgo et al. 2007, Light Rail Now 2006) 


\section{Stations}

Other than guideways, stations are the most visible infrastructure along BRT corridors. In this paper, stations refer to bus stops, terminals, and all kinds of boarding/ alighting facilities. Their architecture, accessibility, and comfort play a vital role in determining the BRT quality of service (Kittelson \& Associates et al. 2003, Darido et al. 2006). Stations should be planned not only for existing BRT users, but also to attract users from other modes of transportation. Standards for transit facility appearance, cleanliness, and inspection programs must be established. In general, BRT systems provide high-quality shelters with passenger information systems. A passenger survey in Santa Clara, California (Dahlgren and Morris 2003) found that an ideal station is a clean, well-maintained, and patrolled place that also provides accurate schedule information. Thus, stations may not necessarily be equipped with the latest technologies.

The design of shelters also must consider passenger accessibility between the shelter and the vehicle, and between the shelter and the sidewalk. The BRT systems in several Latin American cities (such as Curitiba, Goiania, Sao Paulo, Bogotá, Quito, Mexico City, and León) have adopted the platform mode for boarding and alighting. The platform mode eliminates any difference in elevation between the station and bus platforms and significantly reduces the dwell time. However, the construction of shelters with platforms increases the cost of the entire project.

\section{Park-and-Ride Facilities}

Park-and-ride facilities enable users to access the BRT stations by other modes. In cities where automobiles are the dominant mode of transportation, park-and-ride facilities may encourage BRT usage. Park-and-ride facilities are more common in the non-U.S. systems; examples of this are Brisbane and Bogotá. Moreover, planners may design park-and-ride amenities to include commercial activities (Currie 2006, GTZ 2006). The construction cost of park-and-ride facilities must be evaluated against investments for other BRT infrastructures or provision of better feeder bus service (Vincent 2006).

\section{Transit Oriented Development}

Transit Oriented Development (TOD) refers to the proper planning or integration of transit stations/terminals with commercial activities. This will not only reduce the number of trips a traveler makes per day (GTZ 2006), but also could produce revenue from the lease of commercial space. In general, TOD increases land/property value along the corridor, as experienced in Brisbane, Bogotá, San Francisco, and Washington D.C. (Wright 2004). The opportunity to develop com- 
mercial spaces is a trend and is becoming part of the strategies to contribute to BRT project funds.

\section{Operational Features}

\section{Vehicles}

BRT systems usually use vehicles that are distinct from regular bus service. They often have high-capacity, low-floors, ergonomic seats, and multiple wide doors. These designs contribute to improved ride quality, comfort, and reduction in dwell time. The use of articulated buses appears common. Nonetheless, articulated buses are recommended only when high capacity is desired without the need for increasing the frequency of service along the line (Kittelson \& Associates et al. 2003). The design of vehicle should be considered together with station and shelter designs. A key issue when selecting/designing BRT vehicle is the interior design. In some cases, the interior of a vehicle may be comfortable for riders. Beijing's BRT is an example of an inadequate design since the capacity of its $60-\mathrm{ft}$ buses is barely higher than a conventional bus (GTZ 2006). Low-floor vehicles can reduce boarding time (Levinson et al. 2003a, 2003b). Asian and Latin American cities with a high passenger demand opt to use high-floor vehicles for better ride quality (better mechanical suspension).

\section{Route Coverage and Service Frequency}

The TCQSM describes route coverage as the area covered by a particular route within walking distance ( $400 \mathrm{~m}$ for a bus stop, or $800 \mathrm{~m}$ from a terminal) (Kittelson \& Associates et al. 2003). Area coverage by BRT systems is necessary to attract ridership. However, extensive area coverage may lead to frequent stops and longer travel time.

Service frequency is one of the measures of transit service quality. A high frequency implies lower average wait times for customers. This feature usually attracts ridership and is a key component in the total travel time (Kittelson \& Associates et al. 2003). In the U.S., BRT service headways range from 3 to 20 minutes, while in Latin American countries the headways vary from less than 1 minute (Sao Paulo and Porto Alegre) to 10 minutes, depending on the time of day. In countries with high passenger demand, such as Kunming and Seoul, the average headway during the day is continuously less than 1 minute (Wright 2004).

In terms of capacity, which is dependent on the combined effect of vehicle capacity, route coverage, and service frequency, BRT vehicles or fleets can also be com- 
petitive with rail-based mass transit systems. One of the greatest misconceptions of BRT systems is that they are unable to reach high-capacity operation. Wright (2004) reported that Bogotá's BRT moves approximately 36,000 passengers per hour per direction, and the Sao Paulo BRT transports up to 30,000 passengers per hour per direction. Both systems use high-capacity articulated vehicles. In U.S., the highest capacity can be found in the Lincoln tunnel in New York with a capacity of 25,000 passengers per hour per direction (Vincent 2006). BRT systems in the U.S. usually have lower passenger demand, which leads to lower design capacities compared to systems in Asian and Latin American cities (Cain et al. 2007).

\section{ITS Technologies Applied to BRT}

ITS technologies are being implemented more commonly in European, North American countries, and Australia than in developing countries. BRT systems in developing countries are still limited in ITS supplications because of the capital and operating costs (Wright 2004). ITS technologies mainly contribute to the image, safety, and operating speed (Kittelson \& Associates et al. 2003, Darido et al. 2006, Currie 2006, Sakamoto et al. 2007) but are not essential features for a successful BRT system. The BRT systems in Bogotá, Quito, Beijing, Mexico City, and all Brazilian systems are successful examples that have not implemented or have very limited ITS technologies.

Transit Signal Priority (TSP), real-time passenger information systems, and Automatic Fare Collection (AFC) are examples of typical ITS applications in BRT systems. Implementation of TSP has grown rapidly among the U.S. transit systems. Real-time passenger information systems increase productivity of passengers while waiting for buses, avoid crowding at stations, and enhance the image of the shelters (Kittelson \& Associates et al. 2003). Automatic Vehicle Location (AVL) systems help track the locations of vehicles, which can be used for real-time fleet management and future planning purposes. The global positioning system-based AVL system is perhaps the most popular among the available location technologies (Gillen and Johnson 2002). One of the new ITS technologies for BRT is lane-assist systems being implemented in the BRT systems in Orlando and Minneapolis. Lane assist permits BRT vehicles to operate at higher operating speeds with improved safety (Kulyk and Hardy 2007). Precision docking technology (implemented in Las Vegas, but more popular in European cities) helps reduce dwell time.

\section{Fare Collection Methods}

Automatic fare collection (AFC), although originating in other transit systems, has become a regular feature of BRT systems worldwide. Advanced AFC with a common 
smart card allows integration of several modes in one single system, which offers customer convenience (GTZ 2006). In surveys carried out among transit users in Hong Kong, Taipei, New Delhi, London, Oslo, Copenhagen, Washington D.C., San Francisco, Chicago, Rome, Bangkok, Seoul, and Istanbul, smart cards were noted as being effective in promoting ridership, increasing customer satisfaction, improving boarding time, and increasing ease of access (Boushka 2006). AFC usually generates important data for demand forecasting and operational planning (Hidalgo et al. 2007). However, three recent examples demonstrate that AFC may not be as beneficial as it appears. The first example is AFC on the Silver Line in Boston. AFC equipment initially was implemented with the purpose of saving running time. However, contrary to expectations, the travel time increased after AFC implementation. Such experience illustrates the importance of dwelling time control (Darido et al. 2006). The second and third examples are the Quito and Jakarta BRT systems, where the implementation time for user adaptation to AFC technology has been considerably short, causing "insufficient testing and quality assurance." In addition, their fare collection systems are not compatible with other public transportation modes or even among different BRT corridors in the same city (Hidalgo et al. 2007).

\section{Operating Speed}

Operating speed depends on many factors such as guideways, number of stops, dwell time, etc. When Bogotá's TransMilenio was first implemented, the operating speed went from approximately $15 \mathrm{~km} / \mathrm{h}$ to $26.7 \mathrm{~km} / \mathrm{h}$ (Cain 2007). In Seoul, the operating speed of buses has improved after the implementation of BRT in 2004 (by $2.7 \mathrm{~km} / \mathrm{h}$ to $11 \mathrm{~km} / \mathrm{h}$, depending on the corridor), and the speed has increased as users become more familiar with the system (GTZ 2006). Operating speed has a direct impact on ridership attraction. As the name implies, BRT service should be "rapid."

\section{Travel Time and Ridership Attraction}

Of the BRT features reviewed above, all are aimed at reducing travel time or increasing ridership. Therefore, travel time savings (for users) and ridership attraction (for agencies and operators) are the most important design goals. In fact, the most distinctive features of BRT systems are the ones that contribute most to reduction in travel time (such as guideways, high-capacity vehicles, high service frequency, TSP, AFC) and ridership attraction (such as enhanced stations and shelters, transit oriented development, real-time passenger information systems, route coverage). 


\section{Other Related Benefits}

\section{Environmental}

A single BRT vehicle may replace as many as 50 automobiles along a corridor, thus reducing total emissions (GTZ 2006). Environmentally-friendly vehicles are often highlighted as a branding feature of BRT systems. This is particularly important to the U.S. cities that seek federal funding (from FTA) to start BRT services.

\section{Safety}

Guideway and intersection geometric treatments may improve overall corridor safety to better-than-pre-BRT levels. The corridor designs that eliminate conflicts between BRT buses and other vehicles or pedestrians usually produce safety benefits. Seoul and Bogotá have seen reductions in the number of accidents by 27 percent and 93 percent, respectively, compared to pre-BRT conditions (GTZ 2007).

\section{Recommended Deployment Phases}

The above BRT features are those most commonly found in operational systems. However, not all features must appear for a system to be called BRT. As feature selection and design depend on the project budget, local users, and traffic and corridor characteristics, the authors have grouped feature combinations in three deployment phases. Infrastructure features are listed in Table 2, and operational features are listed in Table 3. The three phases are limited, moderate, and aggressive, in increasing order of system cost, ridership attraction, and operating speed. The recommended features in Tables 2 and 3 may be viewed as market packages in the different deployment phases. Note that not all the features listed in each of the phases in Tables 2 and 3 must be followed strictly.

The three deployment phases may be implemented progressively, starting from limited phases when funds are limited and ridership is uncertain. The limited phase consists of features that can be implemented in relatively short time at relatively low costs. This setup is particularly suitable for most U.S. cities because of the initial low ridership and high right-of-way cost. Once the limited-phase BRT has gained acceptance by policy makers and users, and with increasing ridership and experience, the system may be upgraded to the moderate or aggressive phases. That is, the sequence of deployment does not need to be in sequential order. If the right-of-way and funds are readily available, a transportation agency may opt to implement the aggressive phase directly without having to go through the first two phases. Note that it is also possible to upgrade one feature at a time, 
for example AFC. Therefore, the shift from one deployment phase to the next may take place gradually over time.

\section{Summary}

This paper has reviewed and summarized the infrastructure and operational features of BRT systems worldwide. Most of the BRT systems reviewed share common but not all BRT features. When designing a BRT system, the features should be selected according to project budget, local users, and traffic and corridor characteristics and combined to produce maximum ridership attraction and operating speed. Taking into consideration the limited BRT success and ridership and high right-of-way cost in U.S. cities, the BRT features have been grouped into three deployment phases. The features recommended in the different phases are in increasing order of cost, engineering sophistication, and implementation time frames, but they also correspond to more positive effects on ridership attraction and operating speed. The phases may be implemented in sequential order for a BRT system to be sustainable.

\section{Table 2. Recommended BRT Infrastructure Features at Different Stages of Deployment}

\begin{tabular}{|c|c|c|c|c|}
\hline \multicolumn{2}{|c|}{ INFRASTRUCTURE FEATURES } & $\begin{array}{c}\text { PHASE } 1 \\
\text { (3000 to } 9,300 \\
\text { pax/trip/day) }\end{array}$ & $\begin{array}{c}\text { PHASE } 2 \\
\text { (3,500 to } 26,000 \\
\text { pax/trip/day) }\end{array}$ & $\begin{array}{l}\text { PHASE } 3 \\
(120,000 \text { to } \\
1,450,000 \text { pax/ } \\
\text { trip/day) }\end{array}$ \\
\hline \multicolumn{5}{|c|}{ GUIDEWAY AND LANE IMPROVEMENT } \\
\hline \multicolumn{2}{|l|}{ Mixed-flow } & $x$ & & \\
\hline \multicolumn{2}{|l|}{ Dedicated guideway } & & $x$ & $x$ \\
\hline \multicolumn{2}{|l|}{ Contra-flow way } & $x$ & $x$ & $x$ \\
\hline \multirow{3}{*}{$\begin{array}{l}\text { Segregated lane or } \\
\text { exclusive guideway }\end{array}$} & Below grade & & & $\mathrm{x}$ \\
\hline & At grade & & & $x$ \\
\hline & Aerial & & & $x$ \\
\hline \multicolumn{2}{|l|}{ Queue jumper } & $x$ & $x$ & \\
\hline \multicolumn{2}{|l|}{ Overpass lane } & & & $x$ \\
\hline \multicolumn{2}{|l|}{ Median lane runway } & & $x$ & $x$ \\
\hline \multicolumn{2}{|l|}{ Curb lane } & $x$ & & \\
\hline \multicolumn{2}{|l|}{ Curb extension } & $x$ & & \\
\hline
\end{tabular}




\section{Table 2. Recommended BRT Infrastructure Features at Different Stages of Deployment (cont'd.)}

\begin{tabular}{|c|c|c|c|}
\hline INFRASTRUCTURE FEATURES & $\begin{array}{c}\text { PHASE } 1 \\
\text { (3000 to } 9,300 \\
\text { pax/trip/day) }\end{array}$ & $\begin{array}{c}\text { PHASE } 2 \\
\text { (3,500 to } 26,000 \\
\text { pax/trip/day })\end{array}$ & $\begin{array}{c}\text { PHASE } 3 \\
(120,000 \text { to } \\
1,450,000 \text { pax/ } \\
\text { trip/day })\end{array}$ \\
\hline \multicolumn{4}{|l|}{ STATIONS } \\
\hline Enhanced shelters with seats and lighting & $x$ & $x$ & \\
\hline Air conditioning/heater & & $\mathrm{x}$ & $x$ \\
\hline Level platforms & & $x$ & $x$ \\
\hline $\begin{array}{l}\text { Other amenities (route \& schedule, vending } \\
\text { machines, telephones) }\end{array}$ & & & $x$ \\
\hline Pedestrian crosswalks with signal & $x$ & $x$ & \\
\hline Pedestrian bridge access & & & $x$ \\
\hline Automatic passenger counter & & $x$ & $x$ \\
\hline \multicolumn{4}{|l|}{ PARK-AND-RIDE FACILITIES } \\
\hline Open lot parking & $x$ & $x$ & \\
\hline Multi-level parking & & $x$ & $x$ \\
\hline Transfer areas (inside buildings) & & $x$ & $x$ \\
\hline Bicycle parking & $x$ & $x$ & $x$ \\
\hline Taxi stands & $x$ & $x$ & $x$ \\
\hline \multicolumn{4}{|l|}{ SURROUNDING LAND USE } \\
\hline Sidewalk condition improvements & $x$ & $x$ & $x$ \\
\hline Security systems near stations & & $\mathrm{x}$ & $\mathrm{x}$ \\
\hline Mixed land use near station & $x$ & $x$ & $x$ \\
\hline Commercial activities around stations & & $x$ & $x$ \\
\hline $\begin{array}{l}\text { Clustered business facilities } \\
\text { (integrated building) }\end{array}$ & & & $x$ \\
\hline
\end{tabular}




\section{Table 3. Recommended BRT Operational Features at Different Stages of Deployment}

\begin{tabular}{|c|c|c|c|}
\hline OPERATIONAL FEATURES & $\begin{array}{c}\text { PHASE 1 } \\
\text { (3000 to } 9,300 \\
\text { pax/trip/day) }\end{array}$ & $\begin{array}{c}\text { PHASE } 2 \\
(3,500 \text { to } 26,000 \\
\text { pax/trip/day })\end{array}$ & $\begin{array}{c}\text { PHASE } 3 \\
(120,000 \text { to } \\
1,450,000 \text { pax/ } \\
\text { trip/day })\end{array}$ \\
\hline \multicolumn{4}{|l|}{ VEHICLES } \\
\hline $40 \mathrm{ft}-60 \mathrm{ft}$ articulated & $x$ & $x$ & \\
\hline $80 \mathrm{ft}$ double articulated & & & $x$ \\
\hline Diesel, CNG or electric vehicle & $x$ & $x$ & $x$ \\
\hline Hybrid vehicle & & $x$ & $x$ \\
\hline Low-floor vehicles & & $x$ & $\mathrm{x}$ \\
\hline Multiple entrance-exit doors & & & $x$ \\
\hline Wi-fi service & & & $x$ \\
\hline \multicolumn{4}{|l|}{ INTELLIGENT TRANSPORTATION SYSTEM } \\
\hline Transit signal priority & $x$ & $x$ & \\
\hline Automatic vehicle location & & $x$ & $x$ \\
\hline Real-time information system (at stations) & & $x$ & $\mathrm{x}$ \\
\hline Real-time information system (on board) & & & $x$ \\
\hline Collision warning & & & $x$ \\
\hline Precision docking & & & $x$ \\
\hline Lane-assist system & & & $x$ \\
\hline Automatic steering-guidance system & & & $x$ \\
\hline Automatic speed and spacing control system & & & $x$ \\
\hline Voice and video monitoring & & & $\mathrm{x}$ \\
\hline \multicolumn{4}{|l|}{ FARE COLLECTION } \\
\hline On-board fare collection & $x$ & $x$ & \\
\hline Pre-board fare collection & $x$ & $\mathrm{x}$ & $x$ \\
\hline Cash payment & $x$ & & \\
\hline Magnetic strip cards & & $x$ & \\
\hline Smart cards & & $x$ & $x$ \\
\hline
\end{tabular}




\begin{tabular}{|c|c|c|c|}
\hline OPERATIONAL FEATURES & $\begin{array}{c}\text { PHASE } 1 \\
\text { (3000 to } 9,300 \\
\text { pax/trip/day) }\end{array}$ & \begin{tabular}{|c|} 
PHASE 2 \\
$(3,500$ to 26,000 \\
pax/trip/day $)$
\end{tabular} & $\begin{array}{c}\text { PHASE } 3 \\
(120,000 \text { to } \\
1,450,000 \text { pax/ } \\
\text { trip/day })\end{array}$ \\
\hline \multicolumn{4}{|l|}{ SERVICE AND OPERATION } \\
\hline Marketing identity & $x$ & $x$ & $x$ \\
\hline Reduced number of stops & $x$ & $x$ & $x$ \\
\hline Route length extension & & $x$ & $x$ \\
\hline Increased overage area with multiple routes & & & $x$ \\
\hline High service frequency & & $x$ & $x$ \\
\hline Feeders system & & $x$ & $x$ \\
\hline On-time performance monitoring & & $x$ & $x$ \\
\hline \multicolumn{4}{|l|}{ OPERATING SPEED } \\
\hline Operating speed $<20 \mathrm{mph}$ & $x$ & & \\
\hline Operating speed $>20$ and $<30 \mathrm{mph}$ & & $x$ & \\
\hline Operating speed $>30 \mathrm{mph}$ & & & $x$ \\
\hline
\end{tabular}

\section{Acknowledgement and Disclaimer}

This research is supported by Texas Department of Transportation under Research Agreement 0-5668. The contents and views expressed in this paper are the sole responsibility of the authors.

\section{References}

Boushka, M. 2006. Fare collection update: Putting the "smart" in smart card. Mass Transit Magazine, February 14, 2006. http://www.masstransitmag.com/ print/Mass-Transit/Fare-Collection-Update-Putting-the-Smart-in-SmartCards/1\$346. Accessed June 17, 2008.

Cain, A., G. Darido, M.R. Baltes, P. Rodríguez, and J.C. Barrios. 2007. Applicability of Bogota's Transmilenio BRT system to the United States. Paper 07-1538, Preprints of the 86th Annual Meeting of the Transportation Research Board, CD-ROM.

Currie, G. 2006. Bus rapid transit in Australasia: Performance, lessons learned and futures. Journal of Public Transportation 9(3): 8-14. 
Dahlgren, J., and B. Morris. 2003. Advanced bus stops for bus rapid transit. Final Report for RTA No. 65A028. Institute of Transportation Studies, University of California at Berkeley.

Darido, G., R. Diaz, E. Kim, and P. Schimek. 2006. Performance and lessons from the implementation of BRT in the United States. Paper 07-3446, Preprints of the 86th Annual Meeting of the Transportation Research Board, CD-ROM.

Gillen D. and D. Johnson. 2002. Bus rapid transit and the use of AVL technology: A survey of integrating change. Final Report UCB-ITS-PRR-2002-17. Institute of Transportation Studies, University of California at Berkeley.

FTA. 2007. Bus rapid transit. Federal Transit Administration. http://www.fta.dot. gov/assistance/technology/research_4240.html. Accessed June 17, 2008.

GAO. 2001. Mass transit: Bus rapid transit shows promise. GAO-01-984, United States General Accounting Office.

GTZ. 2006. Planificación de sistemas de bus rápido "midiendo impactos," "servicio al cliente y mercadeo" and "errores en planeación." Deutsche Gesellschaft für Technische Zusammenarbeit (GTZ). Presented at the 2nd international Conference of Sustainable Transportation. Mexico City-Querétaro, CD-ROM.

Hidalgo, D., P.S. Custodio, and P. Graftieaux. 2007. Planning, implementation and operation of BRT systems: The cases of Quito, Bogotá, Leon, Mexico City, Jakarta and Beijing. Paper 07-0938, Preprints of the 86th Annual Meeting of the Transportation Research Board, CD-ROM.

Kulyk, W., and M. Hardy. 2003. ITS enhanced bus rapid transit systems. Federal Transit Administration. http://gulliver.trb.org/conferences/VHA-BRT. Accessed June 17, 2008.

Kittelson \& Associates, KFH Group, Parsons Brinckerhoff Quade \& Douglass, and Hunter-Zaworski. 2003. Transit capacity and quality of service manual (TCQSM). Transit Cooperative Research Program Report 100, 2nd Edition, Part 3. Federal Transit Administration.

Light Rail Now. 2006. Busting "BRT" mythology: LA's Orange Line Busway-Just like rail, but cheaper?" A Photo-Report Reality Check. Part 2. Light Rail Progress. http://www.lightrailnow.org/facts/fa_brt_2006-10a.htm. Accessed August 19th 2008. 
Levinson, H., S. Zimmerman, J. Clinger, S. Rutherford, R.L. Smith, J. Cracknell and R. Soberman. 2003a. Bus rapid transit, volume 1: Case studies in bus rapid transit. Transit Cooperative Research Program Report 90, Transportation Research Board.

Levinson, H., S. Zimmerman, J. Clinger, S. Rutherford, R.L. Smith, J. Cracknell, and R. Soberman. 2003b. Bus rapid transit, volume 2: Implementation guidelines. Transit Cooperative Research Program Report 90, Transportation Research Board.

Sakamoto, K., C. Abhayantha, and H. Kubota. 2007. Effectiveness of a bus-priority lane as a countermeasure for congestion. Paper 07-2263, Preprints of the 86th Annual Meeting of the Transportation Research Board, CD-ROM.

Vincent, W. 2006. BRT, U.S. experience. Presented at the 2nd international Conference of Sustainable Transportation, Mexico City-Querétaro, CD-ROM.

Wright, L. 2004. Bus rapid transit planning guide. Deutsche Gesellschaft für Technische Zusammenarbeit (GTZ), Division 44 Environment and Infrastructure Sector Project, Transport Policy Advice, Germany.

\section{About the Authors}

LuIS David Galicia (Idgalicia@miners.utep.edu) is a Graduate Research Associate at the Center for Transportation Infrastructure Systems at The University of Texas at EI Paso (UTEP). He received a bachelor's degree in civil engineering from the National Polytechnic Institute in Mexico City in 1998, and a master's degree in transportation engineering from University of Southern California in 2003. He joined UTEP in 2006 and has completed research projects related to incident management and evacuation planning. His research focuses bus rapid transit planning.

RUEY L. CHEU (rcheu@utep.edu) is an associate professor at the Department of Civil Engineering at UTEP. He received a Ph.D. from the University of California at Irvine in 1994. He served as faculty at the National University of Singapore for 12 years prior to joining UTEP in August 2006. His research focuses on border transportation with emphasis on transportation planning, public transportation, and transportation security. He is on the editorial boards of Transportation Research Part C: Emerging Technologies and the Journal of Intelligent Transportation Systems, a licensed professional engineer in Texas, and a member of two Transportation Research Board committees, ASCE, IEEE and ITE. 
RANDY B. MACHEMEHL (rbm@mail.utexas.edu) is the Al-Rashid Centennial Professor in Transportation Engineering in the Department of Civil, Architectural and Environmental Engineering at The University of Texas at Austin and is President of the Council of University Transportation Centers. He has a Ph.D. from UTA and has taught and performed research in transportation system operations for more than 25 years. In 2006, he received the S. S. Steinberg Award from the Research and Education Division of the American Road and Transportation Builders Association. For the last three years he has served as Associate Chair of the UTA Civil Engineering Department and became Director of the Center for Transportation Research in 1999. His research interests include solving operational problems of urban freeways, optimizing urban traffic signal systems, and making public mass transportation a more desirable travel mode.

HongChao LIU (Hongchao.Liu@ttu.edu) is an assistant professor in the Department of Civil Engineering at Texas Tech University. Prior to joining Texas Tech University in 2004, he worked as a staff researcher and Principal Investigator at the Institute of Transportation Studies at University of California, Berkeley and was the key developer of California's first adaptive transit signal priority on El Camino Real corridor in San Mateo County. His major research interests include traffic management and control systems, intelligent transportation systems, design and operation of bus rapid transit facilities, and microscopic traffic simulation. He is a member of ITE, ASCE, IEEE and the TRB Committee on Artificial Intelligence and Advanced Computation and has published more than 40 papers and technical reports. 